\title{
ANALISIS FAKTOR EMPATHY KUALITAS PELAYANAN TERHADAP KEPUASAN NASABAH PADA PT. BANK RAKYAT INDONESIA Tbk. BARABAI
}

\author{
Eka Santi Agustina \\ E-mail: Ekasanti@gmail.com
}

STIA AMUNTAI

\begin{abstract}
This study aims to identify factors empthy service quality on customer satisfaction at PT. BANK RAKYAT INDONESIA Tbk Barabai. Analysis techniques used are associative Causal with quantitative approach. The quantitative data in this study a ordinal of the respondents' answers to the question posed in the questionnaire. Value statistics t- empthy path variable influence on customer satisfaction at PT. Bank Indonesia Tbk people. Barabai is 2,562 bigger than t-normal distribution table at 1.96, meaning that there is significant influence between the variables kepuasana empthy with customers at PT. Bank Indonesia Tbk people. Barabai. Empthy variable (X1), that individual attention, understanding specific purposes, building a partner, and the friendliness of the employees make a meaningful contribution in the customer satisfaction.

The results showed a positive and significant influence between empathy factor of service to customer satisfaction at PT. Bank Rakyat Indonesia Tbk Barabai. From the estimation PLS appeared another conclusion that the models studied actual satisfaction can only explain the phenomenon of customer satisfaction Britama savings in PT. Bank Rakyat Indonesia Tbk. Barabai amounted to $68.9 \%$. While the remaining $31.1 \%$ is explained by other variables included in the model and error.
\end{abstract}

Keywords: Service, Satisfaction, and Bank Customer 


\section{PENDAHULUAN}

Perbankan merupakan salah satu sektor ekonomi yang cukup esensial dalam dunia bisnis dan sebagai salah satu kebutuhan serta memberikan kepuasan dan mencipakan kesetiaan pada konsumennya dalam hal ini adalah nasabah. Dapat dikatakan bahwa peranan nasabah dalam dunia perbankan sangatlah vital, karena penghimpun dana dari masyarakat dalam bentuk simpanan ini merupakan sumber dana utama yang diandalkan oleh Bank dalam kegiatan usaha sehari-hari. Bank menurut Undang-Undang RI Nomor 10 Tahun 1998 Tanggal 1 November 1998 tentang Perbankan adalah: "Badan usaha yang menghimpun dana dari masyarakat alam bentuk simpanan dana rakyat banyak menyalurkan kepada masyarakat dalam bentuk kredit dan atau bentuk-bentuk lainnya dalam rangka meningkatkan taraf hidup orang banyak".
Sebagai perusahaan yang bergerak dalam bidang jasa, keberhasilan PT. Bank Rakyat Indonesia Tbk. Barabai sangat dipengaruhi oleh kepuasan nasabah. Karena itu selalu berusaha untuk memenuhi kebutuhan dan memuaska nasabah dengan memberi pelayanan yang terbaik, dengan tetap memperhatikan kepentingan perusahaan dengan dukungan sumber daya manusia yang terampil, ramah, senang melayani, dan didukung dengan teknologi yang handal. Salah satu cara untuk memberikan kepuasan nasabah adalah dengan memberikan layanan prima yang meliputi sikap, skil serta penampilan dalam melayani customer.

Seiring dengan kemajuan teknologi yang semakin pesat, maka semakin banyak tercipta inovasiinovasi baru guna memudahkan manusia untuk melakukan kegiatannya. Imbas dari kemajuan teknologi dirasakan juga di dunia perbankan dimana industri penyedia jasa perbankan harus 
bersaing secara ketat guna menciptakan kepuasan nasabahnya. Kepuasan konsumen atau nasabah merupakan hal pokok yang harus diupayakan agar timbul pada pelayanan yang memuaska konsumen dapat diberikan oleh bank agar dapat bertahan hidup dan mampu memenangkan persaingan. Kepuasan pelanggan telah menjadi konsep sentral dakam teori dan praktik pemasaran, serta merupakan salah satu tujuan esensial bagi aktivitas bisnis. Kepuasan nasabah bisa ditimbulkan oleh sebagai hal yang ada dan melekat pada suatu Bank. Oleh karena itu, titik-titik pelayanan yang sering langsung berhubungan dengan nasabah perlu mendapat perhatian khusus dari pengelola perbankan, seperti misalnya sikap Costumer Service dan Teller.

Kepuasan pelanggan akan membuat pelanggan menjadi loyal kepada perusahaan tersebut dan perusahaan yang berhasil dapat dilihat dari bagaimana perusahaan mempertahankan nasabahnya sehingga mereka setia atau loyal menggunakan jasa yang ditawarkan oleh perusahaan tersebut. Loyalitas pelanggan adalah komitmen pelanggan dari suatu merek, toko atau pemasok berdasarkan sikap yang sangat positif dan tercermin dalam pembelian ulang secara konsisten (Sheth \& Mitaal dalam Tjiptono, 2004:387).

Costumer service dan Teller sebagai salah satu ujung tombak yang selalu langsung berhubungan dengan nasabah dan menjadi salah satu sentral bagi standar pelayanan Bank. Berhubungan dengan fungsinya, Costumer service dan Tellermemegang peranan dimana setiap hari nasabah akan dilayani langsung dan mendapat nilai tertentu di benaknya. Selama melayani nasabah, para costumer service dan teller harus bersikap dan berprilaku tertentu sedemikian rupa hingga mampu menambah nilai kepuasan bagi nasabah yangdilayani. Sikap dan perilaku kurang baik dari seorang costumer service dan teller bisa mngurangi 
kepuasan nasabah yang akhirnya menjadi barometer yang buruk bagi kinerja.

Kualitas pelayanan merupakan suatu bentuk penilaian konsumen terhadap tingkat pelayanan yang diterima (perceived service) dengan tingkat layanan yang diharapkan (expected service). Kepuasan pelanggan dalam bidang jasa merupakan elemen penting dan menentukan dalam menumbuh kembangkan perusahaan agar tetap eksis dalam menghadapi persaingan. Demikian pula dengan bisnis perbankan, merupakan bisnis yang berdasarkan pada azas kepercayaan, masalah kualitas layanan (service quality) menjadi faktor penting dalam menentukan keberhasilan bisnis ini. Hal itu juga terjadi di Bank Rakyat Indonesia di kota Barabai sebagai tempat penelitian ini, kualitas pelayanan merupakan hal penting yang perlu diperhatikan. PT. Bank Rakyat Indonesia Tbk. Barabai harus selalu disesuaikan dengan standar pelayanan, apalagi di tengah-tengah persaingan Bank yang semakin pesat. PT. Bank Rakyat Indonesia Tbk. Barabai dituntut untuk tetap menjaga standar pelayanan dalam setiap produk dan proses pelayanannya. Masyarakat Islam saat ini selakin kritis, sehingga ketika bank konvesional yang selama ini ada kehadirannya ternyata pelayanannya tidak sesuai dengan stadar pelayanan maka akan berakibat merugikan bank itu sendiri dan menghilangkan kepercayaan masyarakat terhadap PT. Bank Rakyat Indonesia Tbk. Barabai. PT. Bank Rakyat Indonesia Tbk. Barabai sebagai salah satu lembaga kepercayaan masyarakat harus mampu memberikan pelayanan yang berkualitas untuk memberikan kepuasan bagi nasabah.

\section{TINJAUAN PUSTAKA}

\section{Kajian Empirik}

Penulis menemukan penelitian Anis Wahyuningsih (2002) tentang kualitas pelayanan dan kepuasan nasabah yang berjudul "Analisa Tingkat Kepuasan Konsumen Berdasarkan Kualitas 
Pelayanan Pada Rumah sakit Umum Kabupaten Karanganyar". Penelitian ini menunjukkan bahwa ada pengaruh yang signifikan antara kualitas pelayanan engan tingkatkepuasan konsumen dan aspek kehandalan (reliability) dari demensi kualitas pelayanan mempunyai pengaruh yang paling dominan terhadap kepuasan konsumen.

Penulis juga menemukan penelitian Junaedi (2002) dengan judul "Analisis Kualitas Layanan Terhadap Kepuasan Nasabah Taplus BNI cabang Surakarta" kesimpulan dalam penelitian ini menunukkan bahwa variabel empathy yang merupakan penjiwaan dan perhatian yang bersifat pribadi kepada nasabah, seperti kemampuan alam memberikan perhatian khusus kepada nasabah, menyediakan waktu untuk nasabah bila menghadapi persoalan, pendekatan pribadi, perhatian akan minat dan kebutuhan nasabah merupkan variabel yang dinilai nasbah taplus BNI Cabang Surakarta seagai hal yang dianggap paling penting dan mempunyai pengaruh yang paling signifikan untuk meningkatkan kepuasan kemudian untuk variabel reliability (kehandalan) responsiveness (daya tanggap), dan assurance (jaminan) merupakan variabel yang dapat dianggap penting dan berpengaruh secara signifikan untuk meningkatkan kepuasan. Sedangkan untuk variabel tngibles belum dinilai sebagai hal yang penting dan berpengaruh secaramsignifikan untuk mningktakan kepuasan.

Mencermati hasil dua penelitian diatas, jelas bahwa penelitian penulis yang mengankat analisis faktor empathy kualitas pelayanan terhadap kepuasan nasabah PT. Bank Rakyat Indonesi Tbk. Barabai akan berbeda. Karena setiap lembaga mempunyai karakteristik yang berbeda-beda dalam upaya untuk memaskan konsumen atau nasabah. Begitu juga dengan PT. Bank Rakyat Indonesia cabang Barabai, akan sangat berkaitan dengan aktifitaas yang 
terjadi sehingga kepuasan nasabah tentunya juga ditentukan oleh pelayanan dalam bentuk sama tetapi dalam sistem yang berbedamaka akan menghasilkan kepuasan yang berbeda. Inilah yang membedakan penelitian yang akan dilakukan penulis dengan penekanan pada perbedaan tempat penelitian.

\section{Kualitas Pelayanan}

Roger dalam Nasution (2004) mendifinisikan kualitas sebagai kecocokan penggunaan yang artinya barang atau jasa dalam rangka memenuhi kebutuhan pelanggan atau costumer. Sedangkan menurut Crosby dalam Nasution (2004) kualitas adalah conformance torequirement, yaitu sesuai dengan yang disyaratkan atau distandarkan, suatu produk memiliki kualitas apabila sesuai dengan standar kualitas yang telah ditentukan dengan meliputi bahan baku, proses produksi, dan produk jadi.

Definisi dari pelayanan itu sendiri menurut Sugiarto (2000) adalah upaya maksimal yang diberikan oleh petugas pelayanan dari sebuah perusahaan industri untuk memenuhi harapan dan kebutuhan pelanggan, sehingga tercapai kepuasan. Ranvas dalam Kuswandi (2004) mengungkapkan pengertian pelayanan, yaitu uaya dalam memenuhi permohonan untuk menspesifikasikan produkproduk seperti data kinerja, pesanan, dan layanan garansi.

\section{Dimensi Kualitas Pelayanan}

Terdepat 5 dimensi kualitas pelayanan menurut Parauraman dalam Lupiyoadi (2001), yaitu: reliabiliti atau keandalan adalah kemampuan perusahaan untuk memberikan pelayanan sesuai dengan yang dijanjikan secara akurat dan terpercaya. Tangiblesadalah bukti fisik kemampuan perusahaan dalam menunjukkan ekstensinya kepada pihak eksternal yang dimaksud bahwa menampilan dan kemampuan sarana dan pra sarana fisik perusahaan dan keadaan lingkungan sekitarnya merupakan bukti nyata yang diberikan. Responsipenisssuatu kemampuan 
untuk membantu dan memberikan pelayanan yang cepat dan tepat kepada pelanggan dengan penyampaian informasi yang jelas. Assuranceadalah kesopansantunan perusahaan dan kemampuan para pegawai perusahaan untuk menumbuhkan rasa percaya para pelanggan kepada perusahaan terdiri dari beberapa kompunen antara lain komunikasi, kredibilitas, keamanan, kompetenti, dan sopan santun. Empatyadalah memberikan perhatian yang tulus dan bersifat individual atau pribadi yang diberikan kepada para pelanggan dengan berupaya memahami keinginan pelangga.

\section{Kepuasan Nasabah}

Kepuasan pelanggan adalah seberapa jauh persepsi kinerja sebuah produk sesuai dengan harapan - harapan seorang pembeli (Kotler dan Amstrong, 2004:793). Salah satu hal yang diperlukan dalam mencapai loyalitas nasabah adalah kepuasa. Kepuasan nasabah hanya dapat tercapai dengan memberikan pelayanan yang berkualitas kepada nasabah. Produk yang ditawarkan juga dapat berpengaruh kepada kepuasaan nasabah, semakin baik fitur - fitur atau kualitas yang ditawarkan pada produk tersebut, maka nasabah dengan sendirinya akan merasa puas. Oleh sebab itu, Bank harus mampu melakukan inovasi terhadap produknya agar produk tersebut memiliki nilai tambah daripada produk bank lain. Jika nasabah dapat merasakan nilai tambah dari produk tersebut maka dengan sendirinya kepuasan nasabah dapat tercapai.

\section{Pelanggan}

Manusia memiliki akal budi kemampuan untuk kreatif dan inovatif dalam menciptakan sesuatu, sehingga manusia secara ilmiah harus mmenuhi semua kebutuhan itu dengan cara membeli maupun menukar barang atau jasa yang diinginkan. Terciptanya manusia sebagai pembeli yang dalam dunia industri disebut pelanggan untuk melakukan transaksi dalam rangka memenuhi semua kebutuhan. Arti 
pelanggan menurut Dharmmesta dan Handoko (1997), yaitu individuindividu yang melakukan pembelian untuk memenuhi kebutuhan pribadinya atau konsumsi rumah tangga. Seiring dengan pernyataan Pamitra (2001), yaitu pelanggan adalah individu pembuatan keputusan yang menyebabkan seseorang harus terlibat atau tidak dalam pembelian suatu produk.

Menurut Supranto (2001), yaitu pelanggan adalah setiap individu yang menerima suatu jenis barang atau jasa dari beberapa orang lain untuk kelompok orang. Lopiyoadi (2001) yaitu mengedentifikasikan pelanggan adalah setiap individu yang secara continuedan berulang kali datang ke tempat yang sama untuk memuaskan keinginanya dengan memiliki suatu produk atau mendapatkan suatu jasa dan memuaskan produk atau jasa tersebut. Individu atau kumpulan individu yang dipengaruhi oleh aspek-aspek eksternal dan internal yang mengarah untuk memilih dan mengkonsumsi barang atau jasa yang diinginkan tersebut sebagai pelanggan (Umar,2003).

Menurut Mulyadi dan Jonny Setiawan (2001;80-81) nasabah dalam bahasa jepang artinya customer itu sendiri adalah tamu terhormat bagi personil Disney World, customer selalu sebandingkan sebagai tamu dan dibanyak perusahaan customer dipandang sebagai bagian dari keluarga mereka.

Menurut Kasmir (2008;174175) baik secara kuantitas maupun kualitas. Secara kualitas artinya jumlah nasabah bertambah cukup signifikan dari waktu ke waktu, sedangkan secara kuantitas artinya nasabah yang didapat merupakan nasabah yang produktif yang mampu memberikan laba bagi bank. Untuk mencapai tujuan tersebut, dapat dilakukan berbagai cara dan salah satunya adalah melalui memberikan kepuasan nasabah atau pelanggan. 


\section{METODE PENELITIAN}

Penelitian ini menggunakan metode kuantitatifdengan menggunakan pendekatan diskriptif analisis dan jenis peneitian berbentuk Cross Sectionaluntuk melihat pengaruh kualitas pelayanan empety mempunyai pengaruh yang signifikan secara farsial terhadap kepuasan pelanggan pada PT.Bank Rakyat Indonesia Tbk. Barabai.

Lokasi penelitian adalah PT.Bank Rakyat Indonesia Tbk. Barabai. Jalan Ir.P.H.M.NOOR NO.19. Dalam penelitian ini yang menjadi populasi adalah seluruh nasabah PT.Bank Rakyat Indonesia Tbk. Barabai. Metode sampling yang digunakan dalam penelitian ini adalah purposive sampling. Menurut Supranto (2006), purposive sampling adalah pemilihan sampel yang bersifat tidak acak dimana sampel dipilih berdasarkan pertimbangan pertimbangan tertentu.Menurut Sugiono (2008:218), purposive samplingadalah teknik pengambilan sampel sumber data dengan pertimbangan tertentu yakni sumber data dianggap paling tahu tentang apa yang diharapkan, sehingga mempermudah penelitian menjelajahi objek atau situasi sosial yang sedang diteliti, yang menjadi kepedulian dalam pengambilan sampel penelitian kuantitatif adalah tuntasnya pemerolehan informasi dengan keragaman variasi yang ada bukan pada banyak sampel sumber data.

Menurut Roscoe (1975) dalam Sekaran (2006), besarnya sampel dalam multivarian penelitian adalah 10 (sepuluh) kali jumlah variabel dalam studi. Sehingga dengan demikian untuk menentukan ukuran sampel penelitian akan mengambil sampel sejumlah 10 kali jumlah variabel yang diteliti. Jadi jumlah sampel yang diambil dalam penelitian ini jumlah variabel dikali 10 dan sampelnya sebanyak 60 orang.

HASIL PENELITIAN DAN PEMBAHASAN

Diskripsi Karakteristik Responden 
Analisis ini bertujuan untuk menggambarkan hasil penelitian yang mempergunakan responden sebanyak 60 orang nasabah pada PT. Bank Rakyat Indonesia Tbk. Barabai mengenai jenis kelamin, usia, pendidikan dan pekerjaan. Responden yang menjadi nasabah PT. Bank Rakyat Indonesia Tbk. Barabai sangat bervariasi. Jumlah responden yang dominan adalah usia 30-39 tahu, yaitu sebanyak 30 orang (30\%) serta responden yang berusia 20-29 tahun sebanyak 23 orang (23\%). Nasabah pada usia dikisarkan $\geq 40$ tahun, dalam memilih perusahaan dengan dominanya responden dikisaran 3039 tahun, menunjukkan bahwa nasabah PT. Bank Rakyat Indonesia Tbk. Barabai sangat memperhatikan sarana Physic, tanggung jawab, responsif, komunikatif, keamanan, kecakapan, pemahaman, kredibilitas, keramahan, kemudahan akses.

Karakteristik Responden

Berdsarkan Jenis Kelamin
Bahwa responden yang berjenis kelamin laki-laki berjumlah 32 orang (32\%) dan yang berjenis kelamin perempuan berjumlah 28 orang (28\%). Hal ini menunjukkan bahwa adanya kesamaan pikiran antara laki-laki dan perempuan tentang kenyamanan dan kepercayaan dalam bertransaksi di PT. Bank Rakyat Indonesia Tbk. Barabai dan paling didominasi oleh jenis kelamin laki-laki, yaitu sebanyak 32 orang (32\%).

\section{Karakteristik Berdasarkan}

Pekerjaan

Bahwa nasabah PT. Bank Rakyat Indonesia Tbk. Barabai yang lebih dominan adalah PNS (Pegawai Negri Sipil) sebanyak 36 orang (36\%) dan POLRI 13 orang (13\%). Sedangkan pegawai swasta 2 orang (2\%), wiraswasta 4 orang (4\%) dan TNI hanya 5 orang (5\%). Seperti kita ketahui PNS sangat menghargai dengan waktu yang mereka miliki dengan dominannya responden yang berprofesi sebagai PNS, menunjukkan bahwa PT. Bank Rakyat Indonesia Tbk. Barabai 
semakin dipercaya dan diyakini memberikan kepuasan pelayanan.

Karakteristik

Berdasarkan

\section{Pendidikan Terakhir}

Bahwa pendidikan terakhir S1 yang menjadi nasabah pada PT. Bank Rakyat Indonesia Tbk. Barabai sebanyak 26 orang (26\%) paling dominan. Sedangkan SLTP 6 Orang (6\%), SLTA sebanyak 18 orang $(18 \%)$, dll sebanyak 10 orang (10\%). Hal ini menunjukkan bahwa nasabah sangat berperan dalam memilih kenyamanan dalam bertransaksi.

\section{Pernyataan Responden Terhadap} Variabel Empathy (X1)

Variabel empathy $(\mathrm{X} 1)$

memiliki 4 (empat) item, yaitu: tentang perhatian secara individual yang diberikan oleh para karyawan PT. Bank Rakyat Indonesia Tbk. Barabai, Tentang usaha yang dilakukan oleh PT. Bank Rakyat Indonesia Tbk. Barabai dalam rangka memahami keperluan secara spesifik oleh para nasabah, tentang membangun minat oleh PT. Bank Rakyat Indonesia Tbk. Barabai dan tentang keramahan karyawan dalam memberikan pelayanan oleh PT. Bank Rakyat Indonesia Tbk. Barabai.

\section{Hasil Uji Validitas dan reabilitas} Instrumen Penelitian

Dengan model pengukuran indikator reflektif, indikator dinilai berdasarkan korelasi antar item skor/komponen skor dengan konstruk skor yang dihitung dengan aplikasi PLS, ukuran refleks dianggap valid jika memiliki nilai loading diatas 0,50 dan atau Tstatistik di atas 1,96 (Solimun, 2011). Output PLS untuk Convergent validity bahwa nilai loading semua item di atas $(>)$ 0,5 an T-statistik di atas 1,96 hal ini disimoulkan bahwa item kuisioner telah memenuhi dapat dilihat pada tabel berikut:

Tabel. 1. Outer Model Pada Uji Validitas

Instrument Penelitian

\begin{tabular}{|cccc|}
\hline & $\begin{array}{c}\text { Empthy } \\
(\mathrm{X} 1)\end{array}$ & $\begin{array}{c}\text { Kepuasan } \\
\text { Nasabah } \\
(\mathrm{Y})\end{array}$ & Validitas \\
\hline X1.4 & 1000 & & Valid \\
Y.1 & & 0,694 & Valid \\
Y.2 & & 0,805 & Valid \\
Y.4 & & 0,570 & Valid \\
\hline
\end{tabular}

Sumber: Pengolahan Data Dengan PLS, 2017 


\section{Discriminant Validity}

Merupakan pengukuran dengan indikator reflektif berdasarkan crossloading dengan variabel latennya. Dari hasil cross loading diperlihatkan bahwa untuk indikator empthy memiliki nilai 1000. Dengan demikian menyatakan bahwa indikator empthy berpengaruh signifikan terhadap kepuasan nasabah pada PT. Bank rakyat Indonesia Tbk. Barabaidapat dilihat pada tabel berikut:

Tabel. 2. Cross Loading Untuk Uji Validitas

\section{Instrumen Penelitian}

\begin{tabular}{|l|c:c|}
\hline & Empthy(X1) & $\begin{array}{l}\text { Kepuasan } \\
\text { Nasabah }\end{array}$ \\
\hline Empthy & $\mathbf{1 0 0 0}$ & 0,399 \\
\hdashline 1.4 & & \\
\hdashline Kepuasan & $-0,108$ & $-0,694$ \\
Nasabah & 0,412 & $\mathbf{0 , 5 0 5}$ \\
$Y .1$ & 0,206 & 0,570 \\
$Y .2$ & & \\
\hline .4 & & \\
\hline
\end{tabular}

Sumber: Pengolahan Data Dengan PLS, 2017

\section{Composite Reliability}

Dari output PLS ditunjukkan

bahwa variabel empthy memiliki nilai composite reliability diatas 0,70 , yaitu sebesar 1.000 sehingga dapat disimpulkan bahwa konstruk memiliki reliability yang baik dapat dilihat pada tabel berikut:

Tabel. 3. Composite Reliability Untuk uji Reliabilititas Instrumen Penelitian

\begin{tabular}{|lcc|}
\hline & $\begin{array}{l}\text { Composite } \\
\text { Reliability }\end{array}$ & Reliabilititas \\
\hline Empthy & 1.000 & Reliabel \\
\hline $\begin{array}{l}\text { Kepuasan } \\
\text { Nasabah }\end{array}$ & 0,230 & Tidak Reliabel \\
\hline
\end{tabular}

Sumber: Pengolahan Data Dengan PLS, 2017

\section{Pengujian Hipotesis}

Nilai statistik jalur pengaruh variabel empathy terhadap kepuasan nasabah pada PT.Bank Rakyat Indonesia Tbk. Barabai adalah 2,562 lebih besar dari nilai t-tabel distribusi normal 1,96, berarti signifikan dan hipotesis diterima dapat dilihat pada tabel berikut:

\section{Tabel. 4. Result For Inner}

\section{Weights}

untuk Menguji Hipotesis

\begin{tabular}{|c|c|c|c|c|c|}
\hline & $\begin{array}{c}\text { Origina } \\
l \\
\text { sampel } \\
\text { Estimas } \\
i\end{array}$ & $\begin{array}{c}\text { Mean } \\
\text { Of Sub } \\
\text { Sampel } \\
\text { s }\end{array}$ & $\begin{array}{c}\text { Standar } \\
d \\
\text { Deviatio } \\
n\end{array}$ & $\begin{array}{c}\mathrm{t}- \\
\text { statis } \\
\text { tik }\end{array}$ & $\begin{array}{c}\text { Hub } \\
\text { ung } \\
\text { an }\end{array}$ \\
\hline $\begin{array}{l}\text { Empth } \\
y \text { - } \\
\text { Kepu } \\
\text { asan }\end{array}$ & 0,345 & 0,302 & 0,135 & 2,562 & $\begin{array}{l}\text { Signi } \\
\text { fikan }\end{array}$ \\
\hline
\end{tabular}


Sumber: Pengolahan Data Dengan PLS, 2017

\section{Koefesien Determinan Total}

Hasil output

PLS

menunjukkan bahwa nilai $R$-Square dimasukkan kedalam rumus maka didapat nilai $\mathrm{Q}^{2}=1-(1-0,311)=$ 0,689 dapat dilihat pada tabel berikut:

Tabel. 5. R-square

\begin{tabular}{lc}
\hline & $R$-Square \\
\hline Empthy (X1) & \\
Kepuasan (Y) & $\mathbf{0 , 3 1 1}$ \\
\hline
\end{tabular}

Sumber: Pengolahan data dengan PLS, 2017

\section{Pembahasan}

Nilai t- statistik jalur pengaruh variabelempthy terhadap kepuasan nasabah pada PT. Bank rakyat Indonesia Tbk. Barabai adalah 2,562 lebih besar dari t-tabel distribusi normal sebesar 1,96, artinya terdapat pengaruh yang signifikan antara variabel empthy dengan kepuasana nasabah pada PT. Bank rakyat Indonesia Tbk. Barabai. Variabel empthy (X1), yaitu perhatian secara individual, memahami keperluan secara spesifik, membangun mitra, dan keramahan karyawanmemberikan kontribusi yang bermakna dalam kepuasan nasabah tersebut. Hal ini didukung dengan adanya beberapa teor, diantaranya adalah sebagai berikut:

$$
\text { Menurut yasmin Setiawan }
$$
empthy adalah menjual dengan menempatkan diri kepada posisi si pelanggan atau lawan bicara.mengerti tipe karakter pelanggan, sehingga jika diketahui tipe karakternya naka kebutuhan emosional pelanggan si pelanggan dapat menggunakan pendekatan yang tepat agar pelanggan akan meras simpati, nyaman dan cocok untuk berbicara dengan penjual. (http://yaminsetiawan.com/cgibin/click.pl?id=/tulisan/tulisan10.ht $\mathrm{ml})$.

\section{Kesimpulan}

Berdasarkanhasil penelitian yang telah dilakukan, diperoleh kesimpulan bahwa kualitas pelayanan, yaitu variabel empaty (secara individual, memahami keperluan secara spesifik, membangun mitra, keramahan 
karyawan) menujukkan pengaruh yang signifikan terhadap kepuasan nasabah di PT.Bank Rakyat Indonesia Tbk. Barabai dari hasil estemasi PLS muncul kesimpulan lain bahwa model kepuasan yang diteliti senyatanya hanya mampu menjelaskan fenomena kepuasan nasabah tabungan Britama di PT.Bank Rakyat Indonesia Tbk. Barabai sebesar $68,9 \%$, sedangkan sisanya $31,1 \%$ dijelaskan oleh variabel lain yang tidak dimasukkan ke dalam model dan error.

\section{Saran}

Berdasarkan hasil kesimpulan tersebut di atas, maka dapat diidentifikasi apa yang perlu dilakukan oleh PT. Bank Rakyat Indonesia Tbk. Barabai dan jajarannya untuk dapat meningkatkan kepuasan nasabah dalam hal ini khususnya nasabah tabungan Britam, yaitu faktor Empthy seperti perhatian, memahami keperluan secara spesifik, membangun minat dan tentang keramahan mesti

ditingkatkan lagi.

\section{DAFTAR PUSTAKA}

Dharmmesta, Basu Swasta dan Hani Handoko, 1997, Manajemen Pemasaran Analisis Pelaku Konsumen, Penerbit BPFE, Yogyakarta

Gaspersz, Vincent. 2002. Manajemen Kualitas Dalam Industri Jasa : Strategi Untuk Memenangkan Persaingan Global Jakarta,

Penerbit PT.Gramedia

PustakaUtama.Ghalia Inddstri.

Kotler dan Amstrong, (2004), Prinsip-prinsip Marketing, Edisi Ketujuh, Penerbit Salemba Empat, Jakarta

Kuswadi. 2004. Cara Mengukur Kepuasan Karyawan. Jakarta: PT ElexMedia Komputindo.

Kasmir. (2005). Etika Customer Service. Jakarta: PT Raja Grafindo Persada

- (2008). Bank dan Lembaga Keuangan Lainnya. Jakarta: PT Raja Grafindo Persada

(2008).Dasar-Dasar Perbankan. Jakarta: PT Raja Grafindo Persada 
Lupiyoadi , Rambat. 2001. Manajemen Pemasaran Jasa. Jakarta : PT. Salemba Empat.

Mulyadi dan Johny Setyawan (2001). Sistem Perencanaan dan Pengendalian Manajemen. Jakarta: Salemba Empat

Nasution, Gasperz 2004, Manajemen Perusahaan Barang dan Jasa

Umar, Husein. 2003. Riset Pemasaran dan Perilaku Konsumen. Jakarta: Gramedia Pustaka Utama.

Pamitra, Teddy. (2001). Perilaku Konsumen dan Komunikasi Pemasaran Bandung: PT Remaja Rosda Karya

Roscoe, 1975, dikutip dari Uma Sekaran, 2006, Metode Penelitian Bisnis, Salemba Empat, Jakarta

Supranto. 2006. Pengukuran Tingkat Kepuasan Pelanggan. Cetakan Ketiga. Rineka Cipta: Jakarta

Sugiyono. (2004). Statistika untuk Penelitian. Bandung: Alfabeta . (2009). Metode Penelitian Bisnis. Bandung:Alfabeta

Solimun, 2011. APLIKASI Statistik Mutakhir, Struktural Equation Modeling (Metode Partial Liast Aquare-PLS), FMIPA
Dan Program Pascasarjana Universutas Brawijaya Malang

Tjiptono, Fandy. 2004. Manajemen Jasa, Penerbit Andi, Yogyakarta 